\title{
As metáforas de Lula: o deslizamento dos sentidos e a ordem política na língua ${ }^{1}$
}

Andréia da Silva Daltoé*

\section{Resumo}

Ao investigar os efeitos de sentido do discurso de Lula durante o tempo em que esteve na Presidência do País, 2002-2006 e 2006-2010, o modo como o uso de metáforas chamou a atenção pelo fato de, à época, o Presidente ter sido alvo de inúmeras críticas, que, em sua maioria, levavam esse modo de dizer para o campo do ilógico, do erro, do desvio. Foi, então, que, observando as metáforas de Lula, formulamos o conceito de metáfora discursiva para explicar que esse funcionamento não é da ordem de equivalências semânticas, mas da ordem de um litígio. Consideramos que, desse modo, o discurso de Lula (DL) faz circular sentidos que mexem/ desestabilizam/reorganizam o lugar da cena de representação do político a partir de um novo modo de enunciar a língua política, interferindo no que Pêcheux (2004) tratou como a ordem política na língua.

Palavras-chave: Metáforas de Lula. Metáfora discursiva. Discurso político.

\section{Introdução \\ O combate filosófico por palavras é uma parte do combate politico. (PÊEHEUX, 1988).}

Durante o espaço-tempo em que Luiz Inácio Lula da Silva ${ }^{3}$ esteve na Presidência do Brasil, de 2002 a 2006 e de 2006 a 2010, tanto o meio jornalístico quanto o acadêmico debruçaram-se não apenas sobre o que o então Presidente disse, mas, principalmente, sobre o modo como disse.

Nas diferentes formas de divulgação desse discurso pela mídia, por exemplo, chamou-nos a atenção o modo como, comumente, apontavam para um estra-

Doutora em Teorias do Texto e do Discurso (UFRGS -2011). Docente do Programa de Pós-Graduação em Ciências da Linguagem da Universidade do Sul de Santa Catarina (PPGCL/Unisul). E-mail: andreia. daltoe@unisul.br

Data de submissão: abr. 2013 - Data de aceite: ago. 2013 http://dx.doi.org/10.5335/rdes.v9i2.3849 
nhamento em relação ao funcionamento do discurso de Lula (DL), em especial, ao funcionamento do que aqui trataremos como metáforas de Lula (ML).

Propondo-se a analisar as ML, muitos textos as apontavam como resultado de um discurso político escorregadio, uma saída para quem não quer ser cobrado pelo que diz, um descompromisso com a realidade ${ }^{4}$. Enfim, o uso de metáforas por Lula aparecia, num efeito de sentido predominante, como desvio, defeito, erro a ser evitado, quando não, mistério a ser desvendado.

De início, entendemos que tal estranhamento somente se justificaria em relação a uma normalidade, nesse caso, a um imaginário de língua política ideal, que, presa a um mundo logicamente estabilizado da língua política brasileira, não veria nas $\mathrm{ML} e$, consequentemente, nos sentidos aí veiculados um modo adequado de dizer essa/nessa língua.

Foi então que passamos a investigar os efeitos de sentido desse discurso no campo da vida política do País, procurando observar o que desse funcionamento serviria de pista para entendermos tamanha polêmica na cena discursiva da política brasileira e que relações de poder marcavam-se nessa contenda.

Todavia, observando o funcionamento das ML e verificando que a concepção de metáfora como figura de linguagem, tal como a concebe o senso comum, parece não ser suficiente para explicar essa materialidade discursiva, será necessário também pensar teoricamente essa noção, que, nesta pesquisa, será fundamentada nos pressupostos teóricos da Análise do Discurso (AD) de linha francesa.

Para a organização do material de análise, partimos de um corpus empírico, formado pela coleta das ML no espaço-tempo de seus dois mandados na Presidência do Brasil, que se transformou em um corpus discursivo à medida que essa materialidade foi sendo trabalhada à luz das noções trazidas da $\mathrm{AD}$ para 0 trabalho analítico. Isso porque, segundo Orlandi:

[...] o objeto discursivo não é dado, ele supõe um trabalho do analista e para se chegar a ele é preciso, numa primeira etapa de análise, converter a superfície linguística (o corpus bruto), o dado empírico, de um discurso concreto, em um objeto teórico, isto é, um objeto linguisticamente de-superficializado, produzido por uma primeira abordagem analítica que trata criticamente a impressão de "realidade" do pensamento, ilusão que sobrepõe palavras, ideias e coisas. (2005, p. 66).

As ML foram selecionadas a partir de dois suportes: 1) capturadas de falas de Lula, em viva voz, na TV, no rádio e na internet, transcritas por nós; 2) capturadas em falas escritas, retiradas de jornais e revistas, desde que trazidas entre aspas, já transcritas no material impresso pesquisado. Ressaltamos, porém, que, em ambos os casos, essas falas sofrem, de alguma maneira, os efeitos de sua transcrição, principalmente em relação à coleta de segundo suporte, pois, mesmo que apareçam entre aspas, na forma de um discurso direto, não podemos pensar que essas "reproduções” estejam isentas 
da movimentação dos sentidos causada pelo registro de um dizer por outro.

Para a coleta desse material, foi necessário atribuir um critério em relação ao que estávamos designando como ML. Foi então que, embora posteriormente fôssemos trabalhar com a noção de metáfora do ponto de vista discursivo, inicialmente, partimos do tratamento teórico que predomina nos estudos de metáfora até hoje desde Aristóteles: a metáfora em sua propriedade de "transportar para uma coisa o nome de outra, ou do gênero para a espécie, ou da espécie para o gênero ou da espécie de um para a espécie de outro ou por analogia" (1998, Cap. 21).

A partir desse entendimento, ao selecionarmos o corpus, fomos verificando diferentes maneiras de as ML materializarem-se na língua, o que nos levou a organizá-las em três principais modos de funcionamento, apresentados na continuidade e seguidos de sequências discursivas de referências (SDrs), que os representam:

1) Funcionamento de tipo 1: metáforas que mantêm a marca de seu processo de relação metafórica posto em jogo, a partir de elementos linguísticos de comparação: tal qual, assim como, que nem, como, etc.:

SDr 1: Vamos trabalhar para ganhar as eleições. Não é uma eleição fácil. É como time de futebol. Quando o time está ganhando de um a zero, de dois a zero, quando o time está ganhando, recua, não quer mais fazer falta, pênalti, fica só rebatendo a bola. E quem está perdendo vem para cima com tudo, e é com gol de mão, de cabeça, de chute, de canela. Não tem jogo ganho ou fácil. (LULA, 2010, grifo nosso) $)^{5}$.

2) Funcionamento de tipo 2: metáforas que condensam o processo de comparação, não explicitando os elementos linguísticos de comparação do primeiro grupo:

SDr 2: A economia é uma roda gigante que não pode parar. (Lula, 16/02/2009) ${ }^{6}$.

3) Funcionamento de tipo 3: metáforas narrativas, ou alusivas, cujas relações não se marcassem por elementos linguísticos de comparação, nem por sua condensação, mas significam pelo modo como remetem a relações estabelecidas entre diferentes elementos, explicadas independentemente de marcas no plano linguístico:

SDr 3: $O$ que aconteceu com o famoso mercado onipotente? Quando o mercado teve a dor de barriga, que não foi uma dor de barriga sim, foi uma diarreia daquela, braba, sabe? Insuportável. Ou seja, quando o mercado teve essa diarreia, quem é que eles chamaram pa salvá-lo, o Estado que eles negaram durante 20 anos. (Lula, 04/08, 2008) ${ }^{7}$.

Essa organização das ML delimitou nossa coleta em três grandes grupos, o que não impede que estes aconteçam simultaneamente. Por exemplo, no caso do funcionamento de tipo 1 , as relações estabelecidas com o como também remetem à metáfora de tipo 3. Ressaltamos, também, que nosso interesse não recai sobre uma categorização da ML, pois 
o objetivo é investigar o deslizamento dos sentidos que essas ML promovem a partir de um tratamento discursivo de sua materialidade, independentemente de sua superfície linguística ${ }^{8}$. Por esse motivo, não entraremos, no presente estudo, na distinção entre metáfora, comparação, símile, alusão, já que, nesses casos, é a forma que orienta a classificação. A nós interessa não a forma, mas o funcionamento posto em jogo pelas ML, representadas, neste trabalho, por SDrs (COURTINE, 2009, p. 54), como um novo modo de os sentidos relacionarem-se na cena discursiva da política brasileira, cujo sujeito enunciador, nas palavras de Pêcheux (1988), "caracteriza[-se] discursivamente por tomadas de posição a favor de certas palavras, formulações, expressões, etc., contra outras palavras, formulações ou expressões, exatamente como uma luta pela produção dos conhecimentos" (1988, p. 209-210).

\section{A cena de representação do discurso político}

Corten, em Discurso e representação do político $(1999)^{9}$, apresenta-nos a política como uma "área funcional, na qual, através das instituições políticas, se realizam as atividades políticas" (1999, p. 37), e político como sendo uma representação dessa cena de relações de forças. Para o autor, a representação do político designa, então, a cena das forças políticas construída pelo discurso: "é a cena onde os elementos que perpassam a sociedade são vistos como 'forças' e vistos como 'forças políticas"' (CORTEN, 1999, p. 37). Ou seja, o político é a realidade de tais forças, colocadas em circulação pelo discurso de uma cena, cuja delimitação constrói-se, para o autor, na forma de um relato, supondo determinada configuração de poder.

Por esse motivo, para Corten (1999), o político como cena das forças políticas - cena construída pelo discurso - corresponde ao modo como a história é narrada, produzindo o efeito de sentido das forças políticas de representação do político e, ao mesmo tempo, sua legitimação, o que acontece com todo e qualquer discurso, e não com um tipo de discurso classificado como sendo em si político.

Para nós, o relato em Corten aproxima-se do próprio conceito de discurso em AD: o discurso como efeito de sentido entre interlocutores. Melhor dizendo, não se pode falar que efeito de relato em Corten e efeito de sentido em $\mathrm{AD}$ sejam equivalentes; o que podemos dizer é que o efeito de relato de Corten pode ser tomado como um efeito de sentido para a AD. Nessa perspectiva, estamos entendendo, assim como Corten, o discurso político como sequências de enunciados, provenientes de uma circulação que se caracteriza pela concorrência entre diversas versões narrativas, possibilitando que algumas delas entrem no terreno do político e legitimem-se como tal.

É esse movimento concorrencial que acontece com o discurso de Lula DL, que, 
interferindo em um imaginário de língua política - aqui tomada como uma língua ideal -, passa a representar uma nova versão do político no cenário do País e, a partir de seu efeito de relato, faz circular uma nova versão desse cenário, faz circular sentidos que mexem/desestabilizam/reorganizam o lugar da cena de representação do político a partir de um novo modo de enunciar a língua política.

Para nós, o DL modifica esse lugar, provocando um rearranjo na história da política no País, por meio de uma determinada versão que vai produzir a nova cena de representação do político, ao instaurar um novo interlocutor, o povo brasileiro, e, consequentemente, novos sentidos. Nas palavras de Indursky, isso "equivale a dizer que certos sentidos que são constituídos a partir de uma determinada interpelação/identificação, a partir de um certo momento, podem ser questionados e um sentido pode tornar-se um outro" (2007, p. 17), instaurando, desse modo, a heterogeneidade no interior de uma língua.

Para nós, as ML podem servir como pistas dessa nova versão.

\section{As ML e o deslizamento dos sentidos}

Observando o funcionamento das $M L$, verificamos que não se tratava de uma estrutura frasal que estabelecesse comparação entre elementos distintos, aproximados em uma relação de similitude. Vimos que elas precisariam ser analisadas a partir dos novos sentidos que o DL faz circular. O que muda da metáfora, tal como é tratada pelo senso comum, para o funcionamento que estamos observando aqui é que, nesse caso, ela mobiliza comparações antes não legitimadas no cenário da política nacional, como apontam as relações estabelecidas a seguir:

a) gasto público/despesas domésticas:

SDr 4: Trato a questão do gasto público com a maior seriedade, tendo por base minha história pessoal. Sou casado há 36 anos e nunca fiz uma despesa que não pudesse pagar. Só comprei TV em cores quando podia. Assim faço com o Brasil. Não queremos deixar as coisas desarrumadas para o próximo governo. Digo que não governo o Brasil, mas cuido do Brasil, assim como cuido da família. (Lula, 23/07/10) ${ }^{10}$.

b) crise/diarreia:

SDr 5: Quando o mercado teve a dor de barriga, que não foi uma dor de barrigazinha, foi uma diarreia daquelas, insuportável... Quando o mercado teve essa diarreia, quem é que eles chamaram para salvá-lo? O Estado que eles negaram durante 20 anos. (Lula, $4 / 12 / 2008)^{11}$.

c) futebol/religião/otimismo:

SDr 6: Tem gente que não gosta do meu otimismo, mas eu sou corintiano, católico, brasileiro e ainda sou presidente do País. Como eu poderia não ser otimista? (Lula, janeiro de 2009) ${ }^{12}$.

É esse mesmo transformado do lugar de presidente que nos remete a Corten, na medida em que essas SDrs 
possibilitam observar um modo de funcionamento do relato que modifica $o$ lugar (até mesmo a existência) da cena de representação do político, fazendo do cenário político brasileiro um espaço de litígio, em que as ML vão fazer deslizar os sentidos para um outro lugar: o lugar das coisas simples, das alusões à vida do homem comum.

Esse movimento tem a ver com o trabalho do sentido em $\mathrm{AD}$ como espaço do múltiplo, do diverso - uma situação de conflito em torno da palavra. Levar em conta esse conflito não diz respeito à procura pela razão, pela verdade das coisas, pela resolução de um problema. Trata-se de uma racionalidade da situação de palavra, que, a cada disputa sobre o que quer dizer falar, remete a um litígio em torno do objeto da discussão e em torno daqueles que o constituem como objeto de discussão, uma vez que, conforme Pêcheux, ao conceituar formação discursiva: “[...] as palavras, expressões, proposições, etc., mudam de sentido segundo as posições sustentadas por aqueles que as empregam, o que quer dizer que elas adquirem seu sentido em referência a essas posições" (1988, p. 160).

É desse modo que observamos nas SDrs 4, 5 e 6 não só o litígio da não relação entre os elementos que o sujeito enunciador coloca em relação, mas também o fato de que, ao mobilizar os sentidos de gasto público/despesas domésticas; crise/diarreia; futebol/religião/otimismo, esse sujeito transgride as normas de um modo de funcionar da língua política como língua ideal e passa a reconfigurá-la a partir de outras possibilidades de um Presidente dizer.

Para nosso trabalho, são as coisas-a-saber-e-a-falar de um Presidente da República que Lula não domina e, em não as dominando, faz os sentidos deslizarem para outros modos de dizer, permitindo que os saberes veiculados nas ML não se deixem aprisionar pelas leis do mundo semanticamente normal (PÊCHEUX, 2006) da política brasileira e, por sua vez, constituindo-se em uma ameaça aos sentidos normatizados - sua subversão.

É contra esse movimento que predominam as muitas análises realizadas sobre as ML no espaço-tempo desta pesquisa, em que o trabalho com os sentidos é negado e, consequentemente, é negado o espaço para a interpretação, pois, num universo do logicamente estabilizado, segundo Pêcheux, os espaços discursivos "repousam, em seu funcionamento discursivo interno, sobre uma proibição de interpretação, implicando o uso regulado de proposições lógicas (Verdadeiro ou Falso) com interrogações disjuntivas ('o estado de coisas' é A ou não A?)" (2006, p. 31). Ou seja, conforme Orlandi, uma vez regida a organização social a partir de tais evidências lógico-práticas, não há lugar para questionamentos, para dúvida, para contradições, enfim, apaga-se "o espaço da interpretação: o dizer é o próprio fato" (1996, p. 20).

É esse lugar que as ML vão subverter por desinstalarem saberes próprios do discurso político no Brasil, processo que podemos observar na SDr a seguir: 
SDr 7: A gente tem que parar com essa bobagem de que político é um ser superior. Não posso rir porque sou político, não posso beber porque sou político, não posso falar palavrão porque sou político. Pode sim. (Lula, 16/02/09) ${ }^{13}$.

$\mathrm{Na}$ SDr 7, o sujeito enunciador desloca o sentido de ser político para fora do nosso imaginário social do que representa ser político no Brasil, reivindicando que se pense esse ser político a partir dele como um homem simples, de origem humilde. Aqui, verificamos a materialidade de um efeito de negação que sofre esse discurso e que o fará lidar com o fato de ser da ordem do impensado um ex-operário chegar à Presidência do País. Ao convocar seu interlocutor a parar com essa bobagem, o sujeito enunciador mexe nas fileiras dos sentidos normatizados da política brasileira, questionando suas verdades e pondo em jogo/risco as coisas-a-saber-e-a-falar de um Presidente, cujo trabalho discursivo abrirá caminho para a interpretação, negando que os sentidos sejam tomados como únicos, enfim, um trabalho que nos levará, conforme Pêcheux, à necessidade de interpretar o real, de desconfiar das reservas de conhecimento acumuladas, do tudo que arrisca faltar à felicidade do sujeito pragmático (2006, p. 34).

Com isso, podemos dizer que o estranhamento causado pelas ML, embora apareça sob as mais variadas justificativas - da pureza da língua à retidão protocolar de um Presidente -, acaba apontando para a maneira como os sentidos mobilizados nesse discurso incomodam, por colocarem em relação elementos distintos - assuntos de polí- tica/assuntos da vida comum -, enfim, por colocarem em relação a não relação.

\section{O funcionamento da metáfora discursiva nas ML}

A partir desse olhar às ML, verificamos que o conceito de metáfora tal como é dado pelo senso comum - figura de linguagem, que põe em jogo elementos por relações de similitude - não mais seria suficiente para explicar o funcionamento das ML: primeiro porque esse funcionamento à luz da $\mathrm{AD}$ não poderia resumir-se nem ao nível da língua, nem ao nível de um ornamento linguístico de plano, o figurado; depois porque estamos observando que as relações estabelecidas entre os elementos postos em jogo não são determinadas por aproximações/ comparações a priori. Com essa passagem, reafirmamos que a metáfora não é o "domingo" do pensamento (PÊCHEUX, 2006, p. 53), mas a condição de existência da língua em todos os seus usos.

A busca por esse tratamento discursivo da metáfora levou-nos ao momento inicial da $\mathrm{AAD}^{14}$, quando a metáfora aproximava-se das relações parafrásticas como uma comparação adequada, a partir de uma zona discursivamente homogênea. Todavia, essa distinção passa a acontecer quando Pêcheux e Fuchs, revisitando os estudos iniciais da $\mathrm{AD}$, apresentam que é necessário liquidar o par sentido próprio/sentido figurado, núcleo/periferia e considerar a metáfora como "o transporte entre dois significantes, constitutivo de seu sentido, e a orientação des-equalizante dessa relação como a condição de aparecimento 
do que, em cada caso, poderá funcionar como 'sentido próprio' ou como 'sentido figurado"' ([1975] 1997, p. 244). ${ }^{15}$

Assim, a metáfora deixa de ser considerada como uma comparação de elementos equivalentes e passa a representar, segundo Pêcheux, um "[...] processo sócio-histórico que serve como fundamento da 'apresentação' (donation) de objetos para sujeitos, e não como uma simples forma de falar que viria secundariamente a se desenvolver com base em um sentido primeiro" (1988, p. 132). Tais considerações nos permitem, então, dizer que a metáfora é sempre uma palavra por outra, mas, nessa relação de transferência (meta-phora), cujos elementos significantes passam a se confrontar, os sentidos não poderiam ser predeterminados por propriedades da língua (PÊCHEUX, 1988, p. 263), mas pelos efeitos de sentidos colocados em jogo nas relações metafóricas.
É deste modo que estamos entendendo as ML, como uma prática discursiva que não se reduz a comparar uma palavra com outra, substituindo elementos lexicais, como crise por diarreia, etc., mas como uma prática em que um sentido estável de uma língua política ideal é investido de sentidos diferentes e estranhos, que vêm pela memória, carregando consigo sentidos da vida simples de retirante nordestino, assalariado...

Sendo assim, no caso das ML, não se trata, portanto, de aproximar um sentido $\mathrm{X}$ de um sentido $\mathrm{Y}$, por relações de semelhança, a partir de um princípio de identidade, cujo resultado representaria a equação $\mathrm{X}+\mathrm{Y}=\mathrm{XY}$. Para nós, as $\mathrm{ML}$ marcam-se por um funcionamento que, ao colocar em relação $\mathrm{X} \mathrm{e} \mathrm{Y,} \mathrm{desfaz} \mathrm{a} \mathrm{ideia}$ de não comutabilidade entre elementos antes tomados como distintos e possibilita um novo modo de dizer, que, como resultado do entrecruzamento do interdiscurso com o intradiscurso, assume, em nosso trabalho, a seguinte configuração:

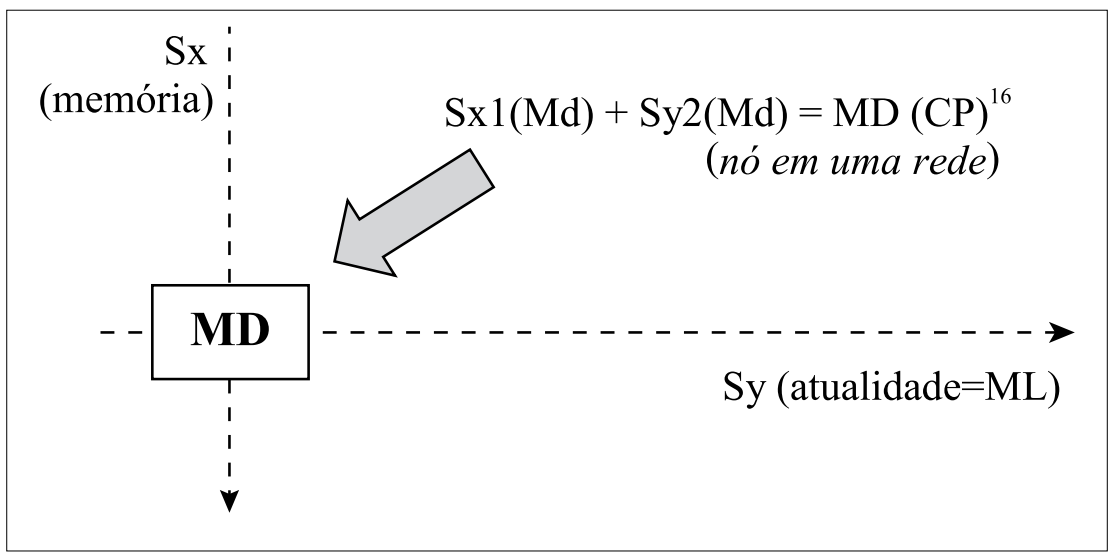

Figura 1: Constituição da Metáfora Discursiva. 
Considerando a metáfora como constitutiva do sentido, sempre determinada pelo interdiscurso, a partir de Pêcheux (1988, p. 263) foi possível, portanto, analisar o funcionamento das ML como pistas de um processo discursivo que fazia deslizar os sentidos de um ideal de língua política para um novo modo de enunciar na cena discursiva da política no Brasil, o que nos permitiu chegar ao conceito de metáfora discursiva (MD) como a substituição de um sentido por outro, justificada no interdiscurso e materializada no intradiscurso sob a forma de uma estrutura metafórica (DALTOÉ, 2011).

Conforme a Figura 1, a MD representa, na materialidade da ML, um nó numa rede, cujo resultado reflete o deslizamento do sentido $\mathrm{X}$ ( $\mathrm{Sx} 1)$, com sua memória discursiva $(\mathrm{Md})$, relacionado ao deslizamento do sentido Y (Sy2), também com sua memória discursiva (Md), da qual o resultado é a ressignificação dos sentidos a partir de suas determinadas CP. Esse funcionamento apresenta, desse modo, a partir de Pêcheux (2011, p. 159), a MD como um curto-circuito simbólico, que "se produz entre dois termos sem que nenhum discurso justificativo o subentenda: as explicações e as justificações virão após" (2011, p. 159), dado o modo como se justificam no interdiscurso, o que podemos observar a partir desta SDr:

SDr 8: Aprendi a contar até dez, apesar de só ter nove dedos, que é para não cometer erros. Um erro em qualquer outro governo é mais um erro. No nosso, não pode acontecer. (Lula, 24/07/2003) ${ }^{17}$.

A partir da Figura 1, teríamos:

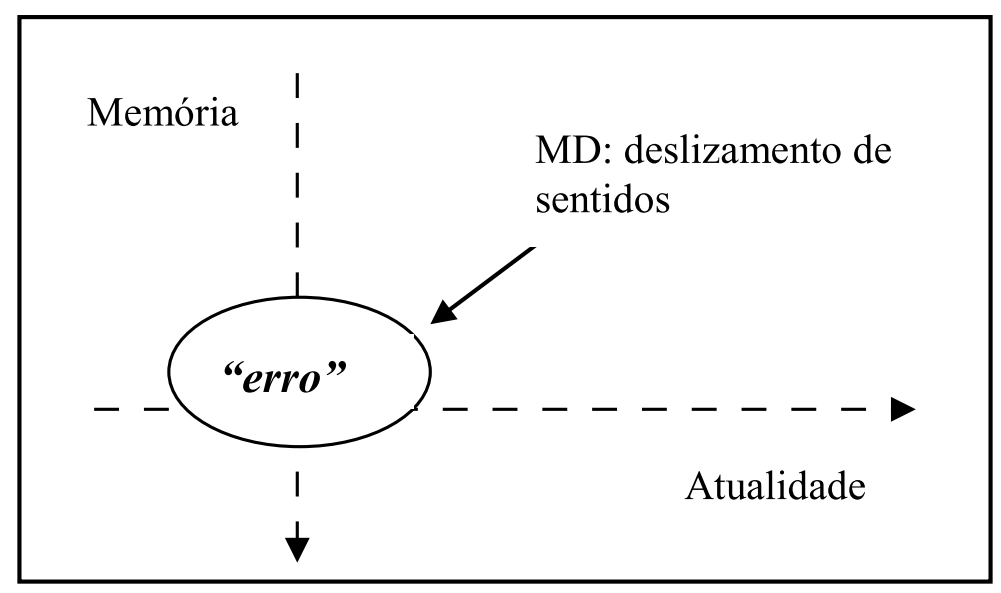

Figura 2: Funcionamento da Metáfora Discursiva 
Com essa figura, podemos pensar em uma memória discursiva que convoca os sentidos do que representou erros em outros governos para serem reinscritos numa atualidade e ajudarem a compor novos sentidos para essa cena discursiva. Como podemos observar na SDr 8, essa articulação justifica-se no interdiscurso e não na língua, pois a MD não coloca em jogo relações entre dois elementos que se aproximam por algum grau de semelhança, por um comum entre eles, mas se ressignificam num espaço de litígio discursivo que, nas palavras de Pêcheux, representa uma tomada de posição a favor de certas palavras, contra outras (1988, p. 209).

Nessa tomada de posição, o sentido de erro no governo Lula, que, fatalmente, vai errar porque não estaria preparado para assumir essa função, acaba afetando/denunciando os erros de outros governos que foram tolerados, num trabalho de deslizamento que, enquanto faz valer um sentido, desfaz e/ou questiona outro.

Nesse caso, o sentido que a metáfora põe em jogo na SDr 8, ao comparar erro de um com erro de outro, somente pode significar a partir do momento em que se convocam as condições de produção em que esse discurso acontece, considerando-se seus efeitos de sentido em relação ao modo como uma memória encontra uma atualidade no funcionamento discursivo da MD. Isso mostra que os sentidos, no deslizamento metafórico, não escorregam do vazio para o vazio, mas carregam consigo a marca de suas determinações históricas, sociais, ideológicas, o que observamos no funcionamento da metáfora em Gadet e Pêcheux ([1981] 2004), segundo os quais a língua funciona como o lugar em que se realiza o retorno dos mesmos dizeres, mas o retorno de um não idêntico sob outras formas.

É desse modo que passamos a ver, no funcionamento das ML, não um recurso estilístico usado pelo Presidente, um desvio daquilo que seria importante/ necessário falar ou uma estratégia de marketing, mas um funcionamento que pode nos dizer muito do discurso político como luta de forças e, muito mais ainda, das determinações ideológicas que afetam a língua.

Observamos, então, nesse processo, que as ML vão provocar fissuras no dizer sedimentado do discurso político, pelo modo como criam novos sítios de significância (COURTINE, 2006). Por isso, estamos considerando que a memória convocada pela metáfora caracteriza, conforme Pêcheux, uma divisão da identidade material do enunciado, fazendo com que "sob o 'mesmo' da materialidade da palavra abre-se então o jogo da metáfora, como outra possibilidade de articulação discursiva [...]” (1999, p. 53). Sendo assim, diferentemente das relações parafrásticas, que se dão num plano horizontal, no nível do enunciado, a metáfora funciona como uma "espécie de repetição vertical, em que a própria memória esburaca-se, perfura-se antes de desdobrar-se em paráfrase" (PÊCHEUX, 1999, p. 53). 
Logo, nesse funcionamento, não se trata de retornar ao mesmo dizer e recolocá-lo em um outro enunciado, em outro lugar - é o não idêntico que trabalha aí, em que a memória é ressignificada, sofrendo o efeito dos furos de sua retomada. Conforme Pêcheux, isso produz um "efeito de opacidade (correspondente ao ponto de divisão do mesmo e da metáfora), que marca o momento em que os 'implícitos' não são mais reconstrutíveis" (1999, p. 53).

$\mathrm{Na}$ análise das ML, conseguimos observar esse movimento da opacidade, verificando que nosso trabalho não poderia se resumir a caçar/descobrir o que estaria por detrás das ML (como objetivaram muitas das análises a respeito), o que, "de fato" o sujeito enunciador desse discurso "intencionava" dizer, mas em verificar aí o trabalho de uma forte mexida nas fileiras dos sentidos.

\section{Algumas costuras finais}

Analisando o funcionamento das ML, foi possível observar que os sentidos da vida simples, do homem simples, invadiram as formas de dizer de um Presidente da República, gerando inúmeros desconfortos, que iam da comparação entre governo e churrascaria ao fato de Lula dizer que tiraria o povo da merda. Lavadas para o espaço do absurdo, verificamos esse estranhamento em relação às ML pode ser entendido como sintoma de uma não aceitação: a não aceitação de que alguém sem estudo pudesse governar o Brasil.
Vimos também que outro sintoma teria a ver com o processo de interlocução que as ML estabeleceram com uma parcela da população que, até então, supostamente não precisaria entender de política. Ao inserir o povo como principal interlocutor, o DL ajudou a desestabilizar um ideal de língua política, inserindo aí questões próprias de uma parcela da população, cujos interesses passaram a representar, discursivamente, o ponto em que a organização dessa língua falha, foge ao controle, deixando trabalhar sentidos interditados que, ao serem trazidos nessa cena, significam pelo curto-circuito simbólico (PÊCHEUX, 2011, p. 159) do encontro da memória com uma atualidade.

É esse curto-circuito que possibilitará às $\mathrm{ML}$, ao produzirem a relação de uma palavra com outra, desestabilizarem fórmulas-prontas de pensamento e ameaçarem a língua fantasmática da política brasileira, representando, assim, conforme Mariani (2007), o funcionamento da língua em sua "resistência à univocidade lógica, resistência às tentativas de domesticação dos sentidos" (2007, p. 66), e, conforme Pêcheux, o modo pelo qual o sentido não se deixa engendrar a si próprio.

Por isso, observamos que o modo de enunciar das ML permite ao sujeito enunciador desse discurso jogar um novo jogo com as próprias regras da língua e, nesse interior, trapacear com elas, provocando um duplo efeito: fazer com que sentidos outros venham ocupar lugares 
antes interditados, ao mesmo tempo em que desfaz/refaz sentidos que sempre foram os únicos possíveis.

Para nós, esse novo modo de enunciar provocou fissuras no ideal de língua política, a qual, segundo Gadet e Pêcheux (2004), sempre tentará conter as formas de subversão, numa "incessante vigilância de tudo o que - alteridade ou diferença interna - arrisca questionar a construção artificial de sua unidade e inverter a rede de suas obrigações" (2004, p. 31). Cerceamento esse que, nas palavras de Orlandi (2002), vai trabalhar na tentativa "de se apagar sentidos, de se silenciar e de se produzir o não sentido onde ele mostra algo que é ameaça" (2002, p. 14). Levar as ML para o terreno do ilógico é (tentar) silenciar essa ameaça.

Assim, enquanto a ordem na língua (PÊCHEUX, 2004) luta por manter os sentidos normatizados, negando, a partir de uma língua marciana ${ }^{18}$, sua história, sua memória; essa ordem (própria) da língua vai perfurando o espaço logicamente estabilizado de um imaginário de língua política ideal. Para nós, as ML são pistas desse processo, porque os sentidos aí, funcionam como: “[...] o índice potencial de uma agitação nas fileiras sócio-históricas de identificação" (PÊCHEUX, 2006, p. 56).

Nessa perspectiva, com base em Pêcheux, as ML surgem atravessadas por uma divisão discursiva entre dois espaços: "[...] o da manipulação de significações estabilizadas, normatizadas por uma higiene pedagógica do pensamento, e o de transformações do sentido, escapando a qualquer norma estabelecida $a$ priori, de um trabalho do sentido sobre o sentido, tomados no relançar indefinido das interpretações" (2006, p. 51).

É desse modo que passamos a ver nas ML um funcionamento que poderia nos dizer muito sobre as determinações ideológicas que afetam a ordem da língua - um funcionamento que, independente das suas marcas linguísticas, diria muito da força do político na língua que, em todas as suas possibilidades de poder, sempre virá acompanhado das tentativas de censura, de cerceamento, de enfraquecimento do que significa dizer de outro modo.

Metaphors from Lula: the sliding of meanings and the political order within language

\section{Abstract}

Along the investigation of the meaning effects from the discourse of Lula within the period he was the president of the country, 2003-2006 and 2006-2010, our attention was drawn to the way his use of metaphor at that time was deeply criticized mostly due to the notion that his language would indicate illogic, error or deviation. Hence, observing the Metaphors from Lula the concept of Discursive Metaphor was formulated in order to explain that the functioning does not belong to the order of semantic equivalences but to the order of a wrangle. This way, in this study the Discourse of Lula (DL) 
makes meanings that tease/destabilize/reorganize the place of the scene regarding the political representation grounded on a new to enunciate the political language, interfering in what Pecheux (2004) treated as the order of political language.

Keywords: Metaphors from Lula. Discursive metaphor. Political discourse.

\section{Notas}

1 Este artigo foi o organizado a partir de capítulos da Tese da autora: As metáforas de Lula: a deriva dos sentidos na língua política, defendida em 2011 pelo Programa de Pós-Graduação em Letras da Universidade do Sul de Santa Catarina - UFRGS.

2 A partir de agora, Lula.

3 Texto publicado no site da Revista Língua, em http://revistalingua.uol.com.br/textos. asp?codigo=10945. Acesso em: 17 fev. 2010.

4 Disponível em: http://www.frasesfamosas.com. br/de/lula.html. Acesso em: 21 jun. 2010.

5 IstoÉ, Especial Brasileiro do ano 2009, em 16/02/2009, p. 76.

6 Declaração do Presidente Lula sobre a crise econômica que atingiu o mundo em 2008. Entrevista transcrita do YouTube, disponível em http://www.youtube.com/watch?v=9y-yb9fzx18\&feature=related. Acesso em: $01 \mathrm{fev}$. 2011.

7 Entendemos superfície linguística, conforme Pêcheux e Fuchs ([1975] 1997), em A propósito da análise automática do discurso: atualização e perspectiva (1975), como um discurso concreto, isso é, como "objeto empírico afetado pelos esquecimentos 1 e 2" (1997, p. 180). In: GADET, F.; HAK, T. (Orgs.). Por uma análise automática do discurso: uma introdução à obra de Michel Pêcheux. Campinas, SP: Editora da UNICAMP, 1997.

8 Publicado em Os múltiplos territórios da análise do discurso (1999), organizado por INDURSKY e LEANDRO-FERREIRA.

9 O Dia online, 23 jul. 2010. Disponível em: http:// odia.terra.com.br/portal/brasil/html/2010/7/ entrevista_com_lula_provamos_ser_barato_cuidar_dos_pobres_dificil_e_cuidar_dos_ricos_98212.html. Acesso em: 27 jul. 2010.
10 Jornal A Notícia. AN. política, em A língua sem freio de Lula, 14/12/2008.

11 Lula, ao prever o exagerado crescimento de $4 \%$ em 2009. Em Revista Veja, 30/12/2009.

12 ISTOÉ, Especial Brasileiro do ano 2009, 16/02/09, p. 76.

13 Análise Automática do Discurso (AAD 69). Tradução: Eni Pulcinelli Orlandi. In: GADET \& HAK (Orgs.). Por uma análise automática do discurso. Campinas, SP: Ed. da UNICAMP, 1997 (a).

14 A propósito da análise automática do discurso: atualização e perspectivas ([1975] 1997).

$15 \mathrm{Sx}=$ sentido; $\mathrm{Md}=$ memória discursiva; $\mathrm{MD}=$ metáfora discursiva; $\mathrm{CP}=$ condições de produção.

16 Lula no lançamento do Plano Safra para a Agricultura Familiar, em 24/07/2003. Disponível em: http://www.doutrina.linear.nom.br/Artigos/ Polemicos/As\%20grandes\%20frases\%20de\%20 Lula.htm Acesso em: 21 jun. 2010.

17 Língua de marciano representa, em Gadet e Pêcheux (2004, p. 23), uma língua universal lógico-matemática, sem memória.

\section{Referências}

ARISTÓTELES. A política. São Paulo: Martins Fontes, 1998.

CORTEN, A. Discurso e representação do político. In: INDURSKY, F.; LEANDRO-COURTINE, J. Metamorfoses do discurso político: derivas da fala pública. Trad. Nilton Milanez, Carlos Piovezani Filho. São Carlos: Claraluz, 2006.

Análise do discurso político: o discurso comunista endereçado aos cristãos. São Carlos: EdUFSCAR, 2009.

DALTOÉ, A. S. As Metáforas de Lula: a deriva dos sentidos na língua política. Porto Alegre: UFRGS, 2011. Tese (Doutorado em Teorias do Texto e do Discurso). Curso de Pós-Graduação em Letras, Universidade Federal do Rio Grande do Sul - UFRGS, Porto Alegre, 2011.

GADET, F.; PÊCHEUX, M. A língua inatingível: o discurso na história da lingüística. 
Trad. de Bethania Mariani e Maria Elizabeth Chaves de Mello. Campinas: Pontes, 2004.

INDURSKY, F.; LEANDRO-FERREIRA, M. C. (Orgs.). Os múltiplos territórios da análise do discurso. Porto Alegre: Editora Sagra Luzzatto, 1999.

INDURSKY, F. Formação Discursiva: ela ainda merece que lutemos por ela? In: INDURSKY, Freda; LEANDRO-FERREIRA, Maria Cristina. Análise do discurso no Brasil: mapeando conceitos, confrontando limites. São Carlos: Claraluz, 2007.

MARIANI, Bethânia Sampaio Corrêa. Silêncio e metáfora, algo a se pensar. In: INDURSKY, Freda; LEANDRO-FERREIRA, Maria Cristina (Orgs.). Análise do discurso no Brasil: mapeando conceitos, confrontando limites. São Carlos: Claraluz, 2007.

ORLANDI, E. P. Interpretação: autoria, leitura e efeitos do trabalho simbólico. Petrópolis: Vozes, 1996.

. As formas do silêncio: no movimento dos sentidos. Campinas, SP: Editora da UNICAMP, 2002.

PÊCHEUX, Michel. O discurso: estrutura ou acontecimento. Campinas, SP: Pontes Editores, 2006.

. Semântica e discurso: uma crítica à afirmação do óbvio. Campinas/SP: Editora da UNICAMP, 1988.

. Metáfora e Interdiscurso. In: Análise de Discurso: Michel Pêcheux. Campinas/ SP: Pontes Editores, 2011.

. FUCHS, Catherine. A propósito da Análise Automática do Discurso: Atualização e perspectivas (1975). Tradução: Péricles Cunha. In: GADET \& HAK (Orgs.). Por uma Análise Automática do Discurso. Campinas, SP: Ed. da UNICAMP, 1997. 